\title{
Bee pollen and honey for the alleviation of hot flushes and other menopausal symptoms in breast cancer patients
}

\author{
KARSTEN MÜNSTEDT ${ }^{1}$, BENJAMIN VOSS $^{2}$, UWE KULLMER $^{3}$, URSULA SCHNEIDER ${ }^{2}$ and JUTTA HÜBNER ${ }^{4}$ \\ ${ }^{1}$ Ortenau Hospital Offenburg-Gengenbach, D-77654 Offenburg; ${ }^{2}$ Justus Liebig University of Giessen, \\ D-35392 Giessen; ${ }^{3}$ Department of Obstetrics and Gynaecology, Asklepios Clinic Lich, D-35423 Lich; \\ ${ }^{4}$ German Cancer Society, D-14057 Berlin, Germany
}

Received March 13, 2015; Accepted April 27, 2015

DOI: $10.3892 /$ mco.2015.559

\begin{abstract}
Hot flushes, night sweats, pain during sexual intercourse, hair loss, forgetfulness, depression and sleeping disturbances are common problems among breast cancer patients undergoing antihormonal treatment. The aim of this study was to investigate whether bee pollen can alleviate menopausal symptoms in patients receiving tamoxifen and aromatase inhibitors/inactivators. We compared a pollen-honey mixture with pure honey (placebo) in a prospective, randomized crossover trial in breast cancer patients receiving antihormonal treatment. The menopausal complaints were assessed using the Menopause Rating Scale (MRS). A total of 46 patients were recruited; $68.3 \%$ (28/41) of the patients reported an improvement in their symptoms while taking honey, compared with $70.9 \%$ (22/31) who reported an improvement with pollen (the difference was non-significant). The results were confirmed by significant improvements in the postmenopausal complaints in the two groups in a pre-post analysis in the MRS and its 3 subscales. This study provided evidence that honey and bee pollen may improve the menopausal symptoms of breast cancer patients on antihormonal treatment. Of note, honey, which was intended to be used as a placebo, produced similar effects as pollen and they both exceeded the extent of a placebo effect in this setting $(\sim 25 \%)$.
\end{abstract}

Correspondence to: Professor Karsten Münstedt, Ortenau Hospital Offenburg-Gengenbach, Ebertplatz 12, D-77654 Offenburg, Germany

E-mail: karsten.muenstedt@og.ortenau-klinikum.de

Abbreviations: GnRH, gonadotropin-releasing hormone; FSH, follicle-stimulating hormone; LH, luteinizing hormone; MRS, Menopause Rating Scale; HDL, high-density lipoprotein; LDL, low-density lipoprotein; IGF, insulin-like growth factor

Key words: bee pollen, hot flushes, menopause, honey, breast cancer

\section{Introduction}

Hot flushes, night sweats, pain during sexual intercourse, hair loss, forgetfulness, depression and difficulties in initiating and/or maintaining sleep are common problems in menopausal women, for which there are several different treatment approaches that been found to be efficient and may be used according to the patient's individual preferences.

Breast cancer patients are more likely to suffer from these problems, as chemotherapeutic treatments may induce temporary or permanent ovarian failure in premenopausal patients. Furthermore, antihormonal treatment with gonadotropin-releasing hormone $(\mathrm{GnRH})$ analogues, tamoxifen, aromatase inhibitors and aromatase inactivators enhances these complaints, occasionally to such an extent that the patient discontinues the medications. The Arimidex, Tamoxifen, Alone or in Combination (ATAC) trial reported discontinuation rates of $14.3 \%$ for tamoxifen and $11.1 \%$ for anastrozole (1). The options for relieving the patients' complaints are limited, as it is generally accepted that they should not receive oestrogen and related substances in order to avoid disease recurrence or progression.

Various substances and methods of managing these conditions have been suggested to alleviate the side effects $(2,3)$, originating from conventional medicine as well as from complementary and alternative medicine. The approaches of conventional medicine include gabapentin, fluoxetine, venlafaxine and clonidine $(4,5)$. However, the adverse effects often limit the general use of these drugs, whereas weight loss, behavioural therapy and exercise appear to be a promising alternative way of reducing hot flushes $(6,7)$.

As none of the aforementioned approaches has convincingly exhibited sufficient efficacy, continued research on the topic is mandatory. Complementary and alternative medical practices suggest administration of vitamin E, soy, black cohosh and red clover. The use of phytooestrogens, however, is not generally accepted, due to possible stimulation of breast cancer cells. Another approach is acupuncture, which has been shown to improve symptoms in several trials, possibly via a calcitonin gene-related peptide (8-11). However, the fact that acupuncture leads to an elevation of oestradiol levels and a decrease in the levels of follicle-stimulating hormone (FSH) and luteinizing hormone $(\mathrm{LH})$ raises concerns regarding its 
safety in breast cancer patients (12). A recent meta-analysis concluded that soy food intake may be associated with prolonged survival, particularly in $\mathrm{ER}^{-}, \mathrm{ER}^{+} / \mathrm{PR}^{+}$and postmenopausal patients (13). These finding and additional research, which demonstrated that oestrogen may induce apoptosis in oestrogen deprivation-resistant breast cancer, clearly suggest that the present concepts of antihormonal treatment must be reconsidered (14). Long-term studies assessing the benefits and risks of methods from complementary medicine are currently lacking. Such studies may be of value, as it has been shown that hot flushes are a strong predictor of breast-cancer-specific outcome, stronger than age, hormone receptor status, or even differences in cancer stage at diagnosis (15).

It was recently demonstrated that pollen mixtures and extracts, as well as bee pollen, may alleviate menopausal symptoms (16-19). This effect was found to be independent of hormonal effects (20-22). Pollen was even found to exert antihormonal effects (23).

A clinical trial was initiated in order to investigate whether bee pollen is efficient in alleviating menopausal symptoms in patients under treatment with tamoxifen and aromatase inhibitors/inactivators.

\section{Patients and methods}

Patient recruitment. We conducted a randomised controlled study comparing a mixture of pollen and honey or pure honey for the alleviation of menopausal symptoms. The criteria for inclusion were as follows: Age $>18$ years, successful surgery without residual tumour, life expectancy of $>12$ weeks, initiation of antihormonal treatment at least 3 months prior to the study, severe menopausal complaints and the ability to read and write in German. The criteria for exclusion were distant metastases, pregnancy or no contraception, allergy to pollen and/or honey, serious concomitant diseases, psychiatric disease, or conventional concomitant treatment for menopausal complaints.

In October 2012, we published a contact request in the local newspapers for breast cancer patients currently under treatment with tamoxifen and aromatase inhibitors/inactivators with severe menopausal complaints. We also contacted patients in our outpatient department who fulfilled the inclusion criteria to inquire whether they were willing to participate in the study.

Patient randomisation. Following written informed consent, the patients were randomised to receive either a mixture of pollen and honey (pollen group) or pure honey (honey group). As there are no available studies on the effect of honey on menopausal symptoms in humans, the treatment with honey was considered to be the placebo. The patients were instructed to ingest a tablespoonful of either substance for the next 14 days and then return for the second assessment and a blood sample. After a free interval of at least another 14 days, crossover to the other study arm was initiated and the participants received the other alternative for a further 14 days. After that period, the patients were invited for reassessment (crossover design).

Stratification by treatment. Due to potential differences in the effects, depending on whether the patients had received tamoxifen or aromatase inhibitors/inactivators, we stratified for these drugs, including at least 15 patients on either treatment. The time period of 14 days was selected in order to be able to assess the efficacy of either intervention and to avoid exposing patients to a possible risk due to unforeseeable interactions.

The pollen and honey used in the study were obtained from Mehler Honig Gmbh (Neichen, Germany). The pollen analysis performed at the Institute for Honey Analyses (Quality Services International $\mathrm{GmbH}$, Bremen, Germany) revealed that the honey was sunflower honey.

Assessment of menopausal complaints. The menopausal complaints were assessed using the Menopause Rating Scale (MRS), as introduced by Schneider et al $(24,25)$ and Heinemann et al (26). This instrument comprises three subscales that measure psychological, somato-vegetative and urogenital complaints. We also assessed demographic data and collected blood samples for measuring triglycerides, high-density lipoprotein (HDL), low-density lipoprotein (LDL) and oestradiol. The background for the analyses of blood lipids is the fact that hormonal treatments may modify blood lipid levels, affecting cardiovascular disease risks, which appear to be higher in breast cancer patients $(27,28)$.

The study protocol was approved by the Ethics Committee of the Justus Liebig University of Giessen, Germany (application no. 103/12).

\section{Results}

Patient characteristics. A total of 46 patients were recruited for this study. The patient characteristics are summarized in Table I. A total of 31 patients $(67.4 \%$; 31/46) completed both phases of the study, whereas 15 patients did not complete the second part of the study. Of the patients treated with honey, 5 discontinued the study after having completed the pollen part and, of the patients treated with pollen, 10 discontinued after having completed the pure honey part, the main reason being distaste for the pollen. On a 10-point taste scale, from 1 (very good) to 10 (very bad), honey received an average score of 2.3, whereas the pollen preparation received an average score of 6.0. There were some minor adverse effects, which are summarised in Table II.

Other treatments. All the patients were assessed on their familiarity with other treatment options for hot flushes and related symptoms. A total of 9 patients had previous experience with such treatments and, on average, they had already tried $>2$. However, the majority of the patients $(37 / 46 ; 80.4 \%)$ had never used any such methods. Overall, the efficacy of the previously tested methods was rated as poor; however, valid analyses were not possible owing to the low number of patients who had attempted such treatments (Table III).

Comparison of honey and pollen groups. The comparison of all the patients receiving pollen or honey revealed an improvement in the postmenopausal complaints in both groups in a pre-post analysis using MRS and its three subscales, with no significant differences between the two groups (Fig. 1). Improvements were reported by $68.3 \%$ (28/41) of the patients receiving honey, 
Table I. Characteristics of breast cancer patients $(n=46)$.

\begin{tabular}{lc}
\hline Characteristics & Values \\
\hline Age at study initiation (years) & $60.8(62.3 ; 11.2)$ \\
Mean (median; SD) & \\
Age at diagnosis (years) & $57.4(58.3 ; 10.8)$ \\
Mean (median; SD) & \\
Time since last check-up ${ }^{\text {a }}$ (months) & $6.0(5.1 ; 3.4)$ \\
Mean (median; SD) & \\
Duration of hormone therapy (months) & $32.5(25.5 ; 28.3)$ \\
Mean (median; SD) & \\
Body mass index & $26.9(26.5 ; 4.5)$ \\
Mean (median; SD) & \\
Karnofsky performance status scale & $91.7(90.0 ; 8.2)$ \\
Mean (median; SD) & \\
Earlier treatment, no. (\%) & \\
Surgery & $46(100.0)$ \\
Radiotherapy & $39(84.8)$ \\
Chemotherapy & $14(30.4)$ \\
Antihormonal treatment, no. (\%) & \\
Tamoxifen & \\
Anastrozole/Letrozole & \\
Exemestan & \\
Fulvestrant & \\
\hline
\end{tabular}

${ }^{a}$ To exclude residual/recurrent disease. SD, standard deviation.

compared with $70.9 \%(22 / 31)$ of those receiving pollen (the difference was not significant). If improvements occurred, they were observed 3-4 days after the initiation of the study, regardless of whether honey or pollen was administered or whether the patients received tamoxifen or an aromatase inhibitor/inactivator as antihormonal medication. Patients taking tamoxifen exhibited a trend towards higher rates of improvement for pollen (86.7 vs. 58.8\%; $\mathrm{P}=0.087$ ).

A pre-post analysis did not reveal any significant differences in the serum levels of cholesterol (total, HDL, or LDL cholesterol), triglycerides or oestradiol.

Patients receiving honey reported a significant improvement in the symptoms associated with the antihormonal medication. In patients taking aromatase inhibitors/inactivators, honey significantly improved symptoms according to the MRS, compared with patients treated with tamoxifen $\left(\mathrm{F}_{\text {Levene test }}=5.75 ; \mathrm{P}=0.022\right)$. The improvements were particularly associated with the urogenital subscale $\left(\mathrm{F}_{\text {Levene test }}=5.36\right.$; $\mathrm{P}=0.027)$ and there was also a trend in the somatic subscale $\left(\mathrm{F}_{\text {Levene test }}=3.85 ; \mathrm{P}=0.058\right)$. However, we also detected a trend towards an increase in oestradiol levels by honey in patients receiving aromatase inhibitors $\left(\mathrm{F}_{\text {Levene test }}=3.79 ; \mathrm{P}=0.060\right)$. Pollen did not exert a significantly different effect on the two types of antihormonal medication.

Effect of oophorectomy on the results. Finally, we investigated whether the presence of the ovaries exerted any effect on the
Table II. Incidence of minor complaints during the study.

\begin{tabular}{lcc}
\hline Complaints, no. & $\begin{array}{c}\text { Honey } \\
(\mathrm{n}=41)\end{array}$ & $\begin{array}{c}\text { Pollen } \\
(\mathrm{n}=36)\end{array}$ \\
\hline Exhaustion & 4 & 2 \\
Increased aggressiveness & 2 & 2 \\
Hot flush on ingestion & 2 & 1 \\
Prickling of lips and mouth & - & 3 \\
Oedema of lower extremities & 2 & - \\
Thin hair & 1 & 1 \\
Mouth odour & 1 & 1 \\
Upper abdominal pain & 1 & 1 \\
Arthralgia & 1 & 1 \\
Flatulence & 1 & 1 \\
Disgust when ingesting the product & 1 & - \\
Nausea & 1 & - \\
Vomiting & 1 & - \\
Heartburn & 1 & - \\
Malaise & 1 & - \\
Headache & 1 & - \\
Red eyes & 1 & - \\
Stronger hot flushes & 1 & - \\
Dizziness & - & 1 \\
Itching of face and extremities & - & 1 \\
\hline
\end{tabular}

Table III. Previous experience with treatments against the side effects of antihormonal treatment $(n=9)$.

\begin{tabular}{lcc}
\hline Methods & $\begin{array}{c}\text { Patients with } \\
\text { experience of } \\
\text { method, no. }(\%)\end{array}$ & $\begin{array}{c}\text { Average rating } \\
\text { of method's } \\
\text { efficacy }^{\mathrm{a}}\end{array}$ \\
\hline Acupuncture & $3(6.5)$ & 3.7 \\
Homeopathy & $7(15.2)$ & 4.0 \\
Vitamin E & $3(6.5)$ & 2.3 \\
Agnus castus & $0(0.0)$ & - \\
Soy & $2(4.3)$ & 4.5 \\
Omega-6 fatty acids & $2(4.3)$ & 4.0 \\
Red clover & $0(0.0)$ & - \\
Traditional Chinese & $1(2.2)$ & 2.0 \\
medicine & $3(6.5)$ & - \\
Relaxation techniques & $0(0.0)$ & 3 \\
Clonidin & $1(2.2)$ & \\
Venlafaxin & & \\
\hline
\end{tabular}

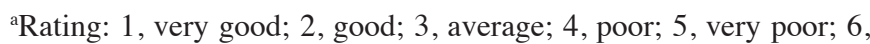
extremely poor.

results and observed that patients who had not undergone oophorectomy benefited more from honey or pollen treatment (present vs. absent ovaries, 73.1 vs. 33.3\%, respectively; $\mathrm{P}=0.063$ ). However, this result did not reach the level of significance, as the number of patients who had undergone oophorectomy was very limited. 


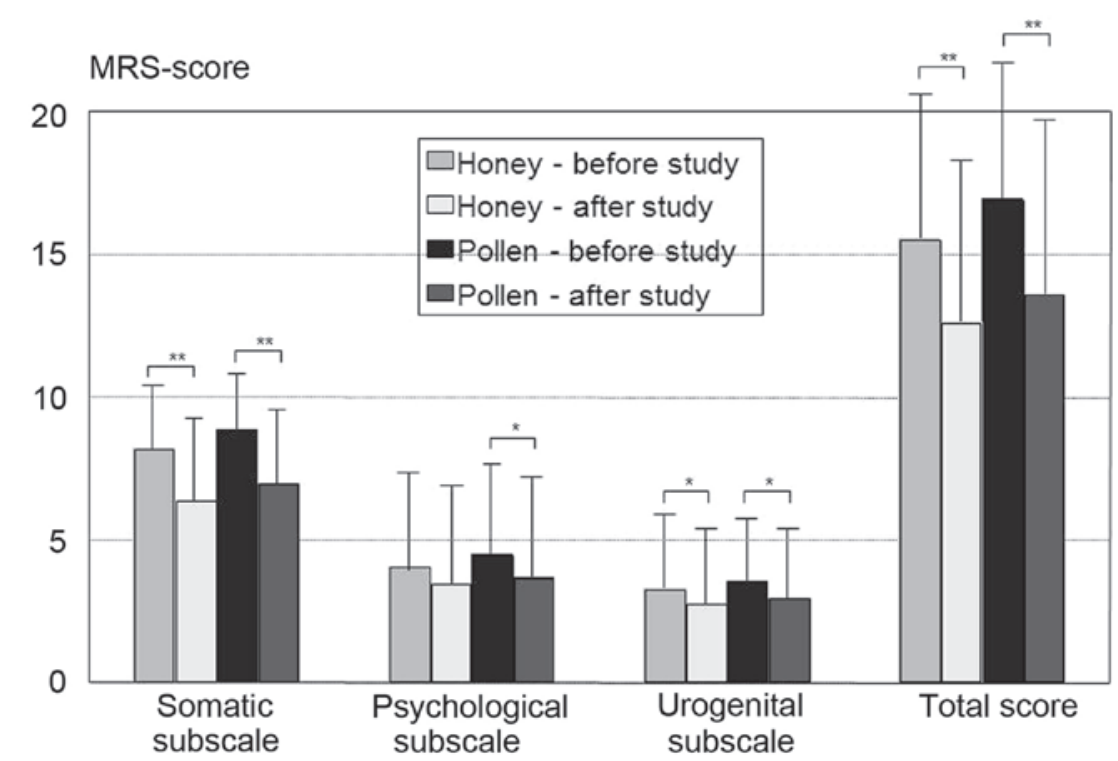

Figure 1. Mean differences in the Menopause Rating Scale (MRS) and its three subscales. Apart from honey in the psychological subscale ( $\mathrm{P}=0.052)$, there were fewer complaints after the use of both pollen and honey. ${ }^{*} \mathrm{P}<0.05$ and $^{* *} \mathrm{P}<0.001$.

\section{Discussion}

In this study, we were able to demonstrate that both honey and the pollen-honey mixture improved menopausal complaints in breast cancer patients. Over two-thirds of the patients who completed the study reported an improvement in their symptoms. Honey was found to be very effective in patients receiving aromatase inhibitors; however, the increase in oestradiol levels may raise some concerns regarding the safety of honey in this setting. Such concerns are not the case with the honey-pollen mixture. It appears that ovaries may play an important role regarding the efficacy of honey as well as that of pollen. It was also demonstrated that neither honey nor pollen exerted a significant effect on serum cholesterol and lipid levels.

Previous studies on the effects of pollen on symptoms in menopausal women formed the basis of this trial (16-19). The mixture of pollen and honey was used as i) it has been demonstrated that a mixture of honey and pollen increases the efficacy of pollen (29) and ii) honey improves the taste of pollen. We demonstrated that the pollen-honey mixture improved menopausal symptoms even in breast cancer patients undergoing antihormonal treatment. Certain patients also reported additional favourable effects, including reduced hair loss (1 case, honey group), improvement in bowel movement ( 1 case, honey group; and 1 case, pollen group) and normalised blood pressure (1 case, honey group).

Of note, honey, which was originally used as placebo and which contains only minimal amounts of pollen, produced effects similar to those of pollen. The extent of the effect observed in this study clearly exceeds that of a placebo effect, which is believed to be $\sim 25 \%$ (30). This may be related to the findings of animal studies, according to which Tualang honey prevented uterine atrophy and increased bone density in ovariectomised rats and was thus considered a possible alternative to hormone replacement therapy (31). However, the positive findings for Tualang honey were achieved only with significantly higher doses (1.0 and $2.0 \mathrm{~g} / \mathrm{kg}$ body weight) (31).
Unfortunately, the increase in the serum levels of oestradiol with honey treatment raises some concerns regarding the safety of honey in patients receiving aromatase inhibitors/inactivators. This finding is of clinical relevance as honey is considered to be a healthy food, which is more frequently consumed by people of higher income and older age ( $\geq 60$ years), particularly women (32). Thus, we may hypothesize that several breast cancer patients on aromatase inhibitors/inactivators consume honey without being aware of this potential risk.

The finding that the presence of ovaries may play an important role in treatment success is supported by an animal study, which demonstrated that the addition of bee pollen to the diet reduced the release of insulin-like growth factor-1 (IGF-1), progesterone and oestradiol from the ovaries (33). This information was not available when our study was initiated. However, there may also be direct oestrogen-like effects, as other experiments demonstrated that bee pollen decreased bone loss, even when the experimental rats were ovariectomised (34).

A limitation of our study was the high drop-out rate, particularly in the honey-pollen mixture group. However, this rate was not as high as that in a comparable study on rhinoconjunctivitis (35). The unusual taste of pure pollen, which may be ameliorated only to some extent by the addition of honey, may limit its potential uses. Another problem is that there have been no chemical analyses of honey and pollen. However, it is well known that honey and, particularly, pollen, contain flavonoids, which are known to reduce the risk of breast cancer $(36,37)$.

A significant finding of our study was the absence of any effect of pollen on serum cholesterol and triglycerides, which was demonstrated in an earlier study by Georgiev et al (17). This may be due to the fact that the majority of the patients included in this study had normal blood lipid levels at the beginning of the study. In accordance with earlier studies, no such effect was expected in the honey group $(38,39)$.

In conclusion, this study provided evidence that honey and bee pollen improve menopausal symptoms in breast cancer 
patients receiving antihormonal treatment. As we observed an increase in the serum levels of oestradiol with honey treatment in patients receiving aromatase inhibitors/inactivators, and due to evidence regarding the effect of honey and bee pollen on ovarian function and the direct effects of these products, honey and bee pollen should be used with caution in cancer patients. Whether this caution is justified remains to be established. As previously mentioned, the scepticism regarding soy products also does not appear to be justified, according to Chi et al (13). Honey and bee pollen may be offered to women who have failed to respond to other reasonable alternatives to cope with postmenopausal symptoms (e.g., acupuncture) and who would otherwise discontinue treatment. However, the fact that flavonoids, which are found in both honey and pollen, have been found to prevent breast cancer, supports the use of both products in women with menopausal problems without a history of breast cancer. The use of honey and pollen for menopausal complaints in healthy women and patients with breast cancer should be addressed in future trials.

\section{Acknowledgements}

We would like to thank the Dr Abel foundation for supporting this trial and all the patients for their participation.

\section{References}

1. Howell A, Cuzick J, Baum M, Buzdar A, Dowsett M, Forbes JF Hoctin-Boes G, Houghton J, Locker GY and Tobias JS; ATAC Trialists' Group: Results of the ATAC (Arimidex, Tamoxifen, Alone or in Combination) trial after completion of 5 years adjuvant treatment for breast cancer. Lancet 365: 60-62, 2005.

2. Loibl S, Lintermans A, Dieudonné AS and Neven P: Management of menopausal symptoms in breast cancer patients. Maturitas 68 : 148-154, 2011

3. Kligman L and Younus J: Management of hot flashes in women with breast cancer. Curr Oncol 17: 81-86, 2010.

4. Lavigne JE, Heckler C, Mathews JL, Palesh O, Kirshner JJ, Lord R, Jacobs A, Amos E, Morrow GR and Mustian K: A randomized, controlled, double-blinded clinical trial of gabapentin 300 versus $900 \mathrm{mg}$ versus placebo for anxiety symptoms in breast cancer survivors. Breast Cancer Res Treat 136: 479-486, 2012.

5. Boekhout AH, Vincent AD, Dalesio OB, van den Bosch J, Foekema-Töns JH, Adriaansz S, Sprangers S, Nuijen B, Beijnen JH and Schellens JH: Management of hot flashes in patients who have breast cancer with venlafaxine and clonidine: A randomized, double-blind, placebo-controlled trial. J Clin Oncol 29: 3862-3868, 2011.

6. Duijts SF, van Beurden M, Oldenburg HS, et al: Efficacy of cognitive behavioral therapy and physical exercise in alleviating treatment-induced menopausal symptoms in patients with breast cancer: Results of a randomized, controlled, multicenter trial. J Clin Oncol 30: 4124-4133, 2012.

7. Caan BJ, Emond JA, Su HI, Patterson RE, Flatt SW, Gold EB, Newman VA, Rock CL, Thomson CA and Pierce JP: Effect of postdiagnosis weight change on hot flash status among early-stage breast cancer survivors. J Clin Oncol 30: 1492-1497, 2012.

8. Frisk J, Källström AC, Wall N, Fredrikson M and Hammar M Acupuncture improves health-related quality-of-life (HRQoL) and sleep in women with breast cancer and hot flushes. Support Care Cancer 20: 715-724, 2012.

9. de Valois BA, Young TE, Robinson N, McCourt C and Maher EJ: Using traditional acupuncture for breast cancer-related hot flashes and night sweats. J Altern Complement Med 16: 1047-1057, 2010.

10. Walker EM, Rodriguez AI, Kohn B, Ball RM, Pegg J, Pocock JR, Nunez R, Peterson E, Jakary S and Levine RA: Acupuncture versus venlafaxine for the management of vasomotor symptoms in patients with hormone receptor-positive breast cancer: A randomized controlled trial. J Clin Oncol 28: 634-640, 2010.
11. Spetz Holm AC, Frisk J and Hammar ML: Acupuncture as treatment of hot flashes and the possible role of calcitonin gene-related peptide. Evid Based Complement Alternat Med 2012: 579321, 2012.

12. Shen X, Du Y, Yan L, Xia Y, Yan H, Han G, Guo Y and Shi X: Acupuncture for treatment of climacteric syndrome - a report of 35 cases. J Tradit Chin Med 25: 3-6, 2005.

13. Chi F, Wu R, Zeng YC, Xing R, Liu Y and Xu ZG: Post-diagnosis soy food intake and breast cancer survival: A meta-analysis of cohort studies. Asian Pac J Cancer Prev 14: 2407-2412, 2013.

14. Ariazi EA, Cunliffe HE, Lewis-Wambi JS, et al: Estrogen induces apoptosis in estrogen deprivation-resistant breast cancer through stress responses as identified by global gene expression across time. Proc Natl Acad Sci USA 108: 18879-18886, 2011.

15. Mortimer JE, Flatt SW, Parker BA, Gold EB, Wasserman L, Natarajan L and Pierce JP; WHEL Study Group: Tamoxifen, hot flashes and recurrence in breast cancer. Breast Cancer Res Treat 108: 421-426, 2008.

16. Winther K, Rein E and Hedman C: Femal, a herbal remedy made from pollen extracts, reduces hot flushes and improves quality of life in menopausal women: A randomized, placebo-controlled, parallel study. Climacteric 8: 162-170, 2005.

17. Georgiev DB, Metka M,Huber JC, Goudev AR and Manassiev N: Effects of an herbal medication containing bee products on menopausal symptoms and cardiovascular risk markers: Results of a pilot open-uncontrolled trial. MedGenMed 6: 46, 2004.

18. Szanto E, Gruber D, Sator M, Knogler W and Huber JC: Plazebokontrollierte Untersuchung von Melbrosia zur Behandlung klimakterischer Beschwerden. Wien Med Wochenschr 144: 130-133, 1994 (In German).

19. Elia D and Mares P: Assessment of the tolerance and effectiveness of a food supplement Sérélys (Femal) for menopausal women. Genesis 135: 12-15, 2008.

20. James LF, Foote W, Nye W and Hartley WJ: Effects of feeding Oxytropis and Astragalus pollen to mice and Astragalus seeds to rats. Am J Vet Res 39: 711-712, 1978.

21. Einer-Jensen N, Zhao J, Andersen KP and Kristoffersen K: Cimicifuga and Melbrosia lack oestrogenic effects in mice and rats. Maturitas 25: 149-153, 1996.

22. Hellström AC and Muntzing J: The pollen extract Femal - a nonestrogenic alternative to hormone therapy in women with menopausal symptoms. Menopause 19: 825-829, 2012.

23. Sarić A, Balog T, Sobocanec S, et al: Antioxidant effects of flavonoid from Croatian Cystus incanus L. rich bee pollen. Food Chem Toxicol 47: 547-554, 2009.

24. Schneider HP, Heinemann LA, Rosemeier HP, Potthoff P and Behre HM: The Menopause Rating Scale (MRS): Reliability of scores of menopausal complaints. Climacteric 3: 59-64, 2000.

25. Schneider HP, Heinemann LA, Rosemeier HP, Potthoff P and Behre HM: The Menopause Rating Scale (MRS): Comparison with Kupperman index and quality-of-life scale SF-36. Climacteric 3: 50-58, 2000.

26. Heinemann LA, Potthoff P and Schneider HP: International versions of the Menopause Rating Scale (MRS). Health Qual Life Outcomes 1: 28, 2003.

27. Chi F, Wu R, Zeng Y, Xing R, Liu Y and Xu Z: Effects of toremifene versus tamoxifen on breast cancer patients: A meta-analysis. Breast Cancer 20: 111-122, 2013.

28. de Sousa-e-Silva EP, Conde DM, Costa-Paiva L, Martinez EZ and Pinto-Neto AM; Sousa-E-Silva EP: Cardiovascular risk in middle-aged breast cancer survivors: A comparison between two risk models. Rev Bras Ginecol Obstet 36: 157-162, 2014.

29. Küpeli Akkol E, Orhan DD, Gürbüz I and Yesilada E: In vivo activity assessment of a 'honey-bee pollen mix' formulation. Pharm Biol 48: 253-259, 2010.

30. Sloan JA, Loprinzi CL, Novotny PJ, Barton DL, Lavasseur BI and Windschitl $\mathrm{H}$ : Methodologic lessons learned from hot flash studies. J Clin Oncol 19: 4280-4290, 2001.

31. Zaid SS, Sulaiman SA, Sirajudeen KN and Othman NH: The effects of Tualang honey on female reproductive organs, tibia bone and hormonal profile in ovariectomised rats - animal model for menopause. BMC Complement Altern Med 10: 82, 2010.

32. Pocol CB: Modelling the honey consumption behaviour in Romania by using socio-demographic determinants. Afr J Agric Res 6: 4069-4080, 2011.

33. Kolesarova A, Bakova Z, Capcarova M, Galik B, Juracek M, Simko M, Toman R and Sirotkin AV: Consumption of bee pollen affects rat ovarian functions. J Anim Physiol Anim Nutr (Berl) 97: 1059-1065, 2013. 
34. Kafadar IH, Güney A, Türk CY, Oner M and Silici S: Royal jelly and bee pollen decrease bone loss due to osteoporosis in an oophorectomized rat model. Eklem Hastalik Cerrahisi 23: 100-105, 2012.

35. Rajan TV, Tennen H, Lindquist RL, Cohen L and Clive J: Effect of ingestion of honey on symptoms of rhinoconjunctivitis. Ann Allergy Asthma Immunol 88: 198-203, 2002.

36. Feás X, Vázquez-Tato MP, Estevinho L, Seijas JA and Iglesias A: Organic bee pollen: Botanical origin, nutritional value, bioactive compounds, antioxidant activity and microbiological quality. Molecules 17: 8359-8377, 2012.
37. Hui C, Qi X, Qianyong Z, Xiaoli P, Jundong Z and Mantian M: Flavonoids, flavonoid subclasses and breast cancer risk: A meta-analysis of epidemiologic studies. PLoS One 8: e54318, 2013.

38. Münstedt K, Hoffmann S, Hauenschild A, Bülte M, von Georgi R and Hackethal A: Effect of honey on serum cholesterol and lipid values. J Med Food 12: 624-628, 2009.

39. Yaghoobi N, Al-Waili N, Ghayour-Mobarhan M, et al: Natural honey and cardiovascular risk factors; effects on blood glucose, cholesterol, triacylglycerole, CRP, and body weight compared with sucrose. ScientificWorldJournal 8: 463-469, 2008. 